\title{
Erratum to: Fitness consequences of habitat variability, trophic position, and energy allocation across the depth distribution of a coral-reef fish
}

\author{
E. D. Goldstein ${ }^{1}$ E. K. D'Alessandro ${ }^{1}$ S. Sponaugle ${ }^{1,2}$
}

Published online: 2 June 2017

(c) Springer-Verlag Berlin Heidelberg 2017

\section{Erratum to: Coral Reefs \\ DOI 10.1007/s00338-017-1587-4}

In Table 1, isotope ellipse area: significance: SS < MP93.4\% should be in bold, but only part of the text is bold (Table 1).

Table 1 Results of statistical analyses comparing depth strata ( $S S$ shallow shelf, $D S$ deep shelf, $M P$ mesophotic) and sample size for each analysis (N)

\begin{tabular}{|c|c|c|c|}
\hline & Test statistic & Significance & $\mathrm{N}_{\mathrm{SS}}, \mathrm{N}_{\mathrm{DS}}, \mathrm{N}_{\mathrm{MP}}$ \\
\hline Predator density Kruskal-Wallis/Dunn's & $\chi_{(2)}^{2}=10.52$ & $\begin{array}{l}\text { DS }>\text { SS \& MP } \\
\text { SS }=\text { MP }\end{array}$ & $120,14,99$ \\
\hline Gut fullness ANCOVA/Tukey's & $F_{(2,70)}=3.98$ & $\begin{array}{l}\text { SS }>\text { DS } \\
\text { MP }=\text { SS \& DS }\end{array}$ & $19,26,29$ \\
\hline Trophic position ANOVA/Tukey's & $F_{(2,52)}=15.44$ & $\begin{array}{l}\text { MP > SS \& DS } \\
\text { SS }=\text { DS }\end{array}$ & $17,17,21$ \\
\hline Isotope convex hull area & $\mathrm{SS}=1.70, \mathrm{DS}=2.14, \mathrm{MP}=4.10$ & - & $17,17,21$ \\
\hline Isotope ellipse area & $\mathrm{SS}=1.06, \mathrm{DS}=1.16, \mathrm{MP}=1.91$ & $\begin{array}{l}\text { SS }<\text { DS } 61.0 \% \\
\text { DS }<\text { MP } 93.3 \% \\
\text { SS }<\text { MP } 93.4 \%\end{array}$ & $17,17,21$ \\
\hline $\mathrm{C}: \mathrm{N}$ ratio ANOVA/Tukey's & $F_{(2,52)}=10.69$ & $\begin{array}{l}\text { MP }>\text { SS \& DS } \\
\text { SS }=\text { DS }\end{array}$ & $17,17,21$ \\
\hline
\end{tabular}

Test statistics for significant comparisons $(p<0.05)$ are in bold. $\mathrm{C}: \mathrm{N}$ is the ratio of mass of carbon to nitrogen in fish muscle tissue. Isotope convex hull area and isotope ellipse area are listed under test statistic. For isotope ellipse area, percentages refer to the probability of pairwise differences in area among depths and were determined from Bayesian credible interval

The original version of this article was revised.

The online version of the original article can be found under doi:10.1007/s00338-017-1587-4.

\section{E. D. Goldstein}

esther.goldstein@noaa.gov

1 Department of Marine Biology and Ecology, Rosenstiel School of Marine and Atmospheric Science, University of Miami, Miami, FL 33149, USA

2 Department of Integrative Biology, Hatfield Marine Science Center, Oregon State University, Newport, OR 97365, USA 